\title{
Is contagion having the last word?
}

\author{
Adamson S. Muula
}

Editor-in-Chief, Malawi Medical Journal and The Africa Center of Excellence in Public Health and Herbal Medicine (ACEPHEM)

Department of Public Health, School of Public Health and Family Medicine, University of Malawi

Email address: amuula@medcol.mw

\section{'Messieurs, c'est les microbes qui auront le dernier mot." Louis Pasteur}

The Severe Acute Respiratory Syndrome Corona Virus 2 (SARS-CoV-2) and the disease it causes, i.e. Covid-19 outbreak $^{1}$, emerged around the same time I had just finished teaching postgraduate students on two widely presented models: the epidemiologic and the demographic transitions ${ }^{2,3}$. In our discussions, we tackled the classical presentations of these two models. The epidemiologic transition posits that as countries become more developed, infectious or communicable diseases contribute a smaller proportion of their overall mortality while non-communicable diseases predominate.

We discussed our own country (Malawi) as perhaps not following this classical route as both communicable and non-communicable diseases were major contributions to the high morbidity and mortality rates being experienced. We had talked about the contribution of mortality from communicable diseases in high income countries generally being dwarfed by a higher burden of non-communicable diseases notwithstanding the mortality due to hospitalacquired infections (HAIs) and anti-microbial drug resistance (AMR). With respect to the demographic transition, this was presented in the way that as countries became more developed, fertility declined, death rates declined also until both (birth and death rates) were very low. Relating to our country, several of the students proposed that we were in Stage 3 of the demographic transition where the death rates were going down, while birth rates were also on the decline but not low enough, hence the total fertility rate (TFR) of 4.4 reports by the 2015 Malawi Demographic and Health Survey ${ }^{4}$.

As at $2^{\text {th }}$ March 2020, Malawi was among the countries within the Southern African Development Community (SADC) not to have registered a single case of Covid-19. Yet, on abundance of caution about ten days earlier, on 20th March 2020, the State President of the Republic of Malawi had directed that all schools be closed and gatherings of at least 100 people be stopped forthwith ${ }^{5}$. The College of Medicine of the University of Malawi had a day earlier delayed the resumption of the academic year after the second semester mid-semester break ${ }^{6}$. Further guidance was given to later discourage large gatherings generally and encourage hand and respiratory hygiene ${ }^{7}$. As what happens with public health interventions of this nature, we are most likely not going to know the effect of such measures, especially when implemented in a context where no cases have been reported. In 2016 the Commission on Global Health Risk Framework for the Future as pre-empting the forthcoming Covid 19 pandemic published a report titled; The Neglected Dimension of Global Security: A Framework to Counter Infectious Disease Crises ${ }^{8}$. This Commission then recommended three strategies namely:

- Strengthening public health as the foundation of the health system and first line of defense;

- Strengthening global and regional coordination and capabilities;

- Accelerating Research and Development (R\&D) to counter the threat of infectious diseases.

The world paid and at the same time did not pay much attention to such guidance. On the one hand, Africa is presently better prepared for such an infectious disease pandemic such as Covid-19. The health systems are being strengthened even when such may have happened through vertical programmes such as the HIV and AIDS US government's PEPFAR initiative. The numbers of professional and non-professional health workers have been increasing although amid growing needs and population and not catching up with demand. Field epidemiology programmes are expanding and the Africa CDC presents an opportunity to contribute to epidemic surveillance, prevention and control. As to curative medical services (even though Covid-19 currently demands only supportive care), that is perhaps the weakness most to be felt should Africa have the numbers and clinical demands that Covid-19 has so far exacted on Europe and the United States have since experienced. While we are hopeful (and I am not sure where I am getting this hope from) that SARSCov 2 may not affect our country the way others have, my fear is whether we will even attempt to provide any care at all to severe cases when the total count of ventilators for our 17 million population is just under two dozen.

While we can only speculate why we have so far been spared, and this could have to do with our limited connectedness to the rest of the globe, such an envied circumstance needs to give us opportunity to converse and work towards strengthening our health systems in peace times. Malawi continues to have a window now where it can recruit more health professionals especially the newly graduated but unemployed doctors, revise the monthly risk allowance for clinical staff from US $\$ 2.5$ to something more reasonable and have a serious conversation on how else to strengthen its health system. Otherwise as Loius Pasteur was quoted as saying: "Gentlemen, the microorganisms will have the last word."

\section{References}

1. Zhu N, Zhang D, Wang W, Li X, Yang B, Song J, Zhao X, Huang B, Shi W, Lu R, Niu P, Zhan F, Ma X, Wang D, Xu W, Wu G, Gao GF, Tan W; China Novel Coronavirus Investigating and Research Team. A Novel Coronavirus from Patients with Pneumonia in China, 2019. N Engl J 
Med. 2020 Feb 20;382(8):727-733. doi: 10.1056/NEJMoa2001017.

2.Gaylin DS ,Kates J. Refocusing the lens: epidemiologic transition theory, mortality differentials, and the AIDS pandemic. Soc Sci Med.1997;44(5):609-21.

3. Gauvreau D, Sabourin P, Vézina S, Laplante B. The mechanics of the baby boom: Unveiling the role of the epidemiologic transition. Popul Stud (Camb). 2018 Nov;72(3):305-321. doi: 10.1080/00324728.2018.1490450.

4. National Statistical Office (NSO) [Malawi] and ICF. 2017. Malawi Demographic and Health Survey Zomba, Malawi, and Rockville, Maryland, USA. NSO and ICF, 2015-16.

5. President of the Republic of Malawi. Presidential Declaration of State on National Disaster, Lilongwe, Malawi, 20th March 2020

6. College of Medicine Registrar. Delaying the opening of the College. University of Malawi, College of Medicine, Blantyre, Malawi, 19th March 2020
7. College of Medicine Registrar. College Wide Response to Coronavirus Pandemic. University of Malawi, College of Medicine, Blantyre, Malawi, 26th March 2020

8. Commission on a Global Health Risk Framework for the Future. The neglected dimension of global security: A framework to counter infectious disease crises. http://nam.edu/GHRFreport, doi: $10.17226 / 21891$ 